\title{
Review of SBR process in effluent treatment
}

\author{
YANG Jing ${ }^{1,2}$, LIANG Wei-lii ${ }^{3}$, and HUANG Fu-chuan ${ }^{1,2^{*}}$ \\ ${ }^{1}$ College of Mechanical Engineering, Guangxi University, Nanning, 530004, Guangxi, China. \\ ${ }^{2}$ Guangxi Key Laboratory of Petrochemical Resource Processing and Process Intensification Technology, Guangxi University. \\ ${ }^{3}$ South China branch of National Petroleum and natural gas pipeline network Group Co., Ltd
}

\begin{abstract}
SBR process evolved from activated sludge process. Because the long cultivation period of activated sludge process and the treatment effect can not meet the needs of production and life, SBR process and related variant improved process came into being. Since the 21 st century, with the development of automatic control technology, SBR process has become a widely used technology. This paper introduces the SBR technology and the related improvement process, and puts forward suggestions for the development of SBR Technology in the field of sewage treatment.
\end{abstract}

\section{Introduction}

In recent years, with the rapid development of economy, with the continuous improvement of people's living standards, it also brings a series of problems, a large number of production and domestic sewage need to be treated urgently is one of them. If the sewage is directly discharged into rivers, lakes and seas without treatment, it is bound to cause environmental pollution. Moreover, with the growth of population, the amount of sewage treatment is increasing rapidly, and the traditional sewage treatment methods cannot meet the requirements of the new era. Based on the traditional activated sludge process, the intermittent activated sludge process was developed in the further research. Nowadays, SBR process is more suitable for the application of automatic control technology in industry, so SBR process has become a research hotspot in the field of sewage treatment. [1]

SBR process can be traced back to 1914, when British experts ardern and Lockett used indirect aeration technology on the basis of activated sludge process, which provided a rudiment for the development of SBR process. [2] In China, the research on SBR process started earlier. SBR process has been studied in China since 1980s, and the first set of sewage treatment equipment based on SBR process was built in Shanghai in 1985. [3] After trial operation, the effect of posttreatment is good, which also proves the vitality of SBR process in the field of effluent treatment. Now, SBR process has been widely used in sewage treatment plants all over China. SBR is the abbreviation of Sequencing Batch Reactor Activated Sludge Process, It is a kind of activated sludge effluent treatment technology operated by intermittent aeration. The core of SBR technology is SBR reaction tank, which integrates the functions of homogenization, primary sedimentation, bio-degradation and secondary sedimentation in one tank, without sludge return system. The degradation law of organic matter in SBR process is similar to that in push flow aeration tank. The push flow aeration tank is push flow in space (length), and SBR reaction tank is push flow in the sense of time.

\section{SBR process for effluent treatment}

Due to the gradual change of organic matter in SBR process, the concentration of organic matter in the tank is high in the initial stage of reaction. When the oxygen supply rate is less than the oxygen consumption, the dissolved oxygen in the mixture tends to zero, which may be intermittent for a single microorganism. Oxygen supply determines the degradation rate of organic matter. With the deepening of aerobic process, the concentration of organic matter will decrease. When the oxygen supply is greater than the oxygen consumption, dissolved oxygen appears in the liquid. Microorganisms can get sufficient oxygen supply. Therefore, the concentration of organic matter has become an important factor affecting the degradation rate of organic matter. The design of aeration system in SBR reaction tank can make the operation of SBR system more economical and reasonable. A SBR complete operation process of the process is divided into five stages.[4] The first stage is the influent stage. After the large solid particles and suspended solids are removed by the grid, the filtrate enters into the tank, which can be pre aerated or stirred for semi aeration as required. The second is the reaction stage, in which agitation or aeration is started in the tank to provide reaction conditions for the aerobic microorganisms to decompose the organic matter in the sewage and remove nitrogen and phosphorus. Then there is the sedimentation period, in which both the agitator and the aerator stop working, which can separate the solid and liquid more effectively, and the sludge settles downward. During the sedimentation period, the reactor

*Corresponding author's e-mail: huangfuchuan@gxu.edu.cn 
is completely static, which is equivalent to secondary precipitation. After the drainage period, the upper clarifier of SBR tank is discharged by the designed drainage pipe or decanter. The excess sludge is discharged by the sludge discharge pipe, and the remaining sludge can be used as the return sludge in the next cycle. The last is the idle period, which is the stage of waiting and preparing for the coming of the next cycle. The discharged sludge will also choose to discharge at this stage or continue to carry out a static sedimentation process. Sometimes, the idle period will not be set.

Compared with other effluent treatment technologies, SBR process has its unique advantages. [5] The process is simple and cost-effective; the process makes full use of and meets the basic principles of biological reaction process and unit operation; SBR tank is suitable for automatic control system, which can change the reaction time according to the influent water quality and quantity.

\section{Study on SBR process}

Many experts and scholars at home and abroad have discussed the influence on the operation of SBR process by changing different conditions, and put forward many factors affecting SBR process for sewage treatment. Zhu Kangkang et al. [6] explored the treatment of pollutants in SBR pool under different light conditions. Li Shanshan [7] and others studied the effects of $\mathrm{Cu} 2+$ on the performance of sequencing batch reactor (SBR) and the characteristics of extracellular polymer (EPS) of activated sludge under long-term exposure. Song Lei et al. [8] explored the efficiency of microbial treatment of sewage in SBR tank in different seasons through design test. Changsheng [9] et al. Established a new short-range nitrification mode by sulfate reducing bacteria, and achieved good denitrification effect in the treatment of thermal power effluent by SBR process. Ning Gaoyang [10] and others explored the influence of carbon nitrogen ratio in effluent on the denitrification removal rate of SBR reactor, and proposed that the carbon nitrogen ratio would significantly affect the microbial population structure in SBR pool. Zhang Zijian et al. [11] explored the influence of different alkalinity on the short cut nitrification process in SBR by taking the $\mathrm{pH}$ value and dissolved oxygen in the tank as variables, trying to find the most suitable $\mathrm{pH}$ value for nitrification in the reactor.

With the deepening of the research on SBR process, the improvement of SBR process has made new progress. They are based on the SBR tank as the main body of improvement, according to their own application of sewage treatment field, such as: medical effluent treatment, urban sewage treatment, livestock effluent treatment and other sewage characteristics to adjust the SBR tank design or aeration scheme. According to the characteristics of high nitrogen compounds in landfill leachate, Cai Liyun [12] and others explored the influence of extended aeration SBR process on the removal rate of nitrogen compounds and analyzed the influence of denitrification microbial population. In the treatment of livestock and poultry effluent, he Zhiming [13] and others have added polyaluminum chloride
(PAC) dosing device in view of the characteristics of more TP (total phosphorus) and suspended solids in livestock and poultry effluent, so as to ensure the standard discharge of effluent. Li Yehui et al. [14] studied the effect of adding $\mathrm{FeCl} 3$ and PAC on the operation of SBR process. Duan Yan [15] and others suspended suspended suspended media in the aeration tank on the basis of SBR tank. Suspended media can increase the living space of microorganisms in the tank, increase the number of microorganisms in the tank, and improve the impact resistance of the reaction tank. Yang Huimin [16] and others add accel to SBR tank, which can significantly improve the activity of microorganisms in the environment, accelerate the microbial treatment of pollutants, and increase the treatment load of the reaction tank. Li Hengyu [17] and others explored the influence of granular activated carbon bed and membrane mixing system on SBR reactor. Shenyang Institute of Environmental Sciences [18] has designed a new patent. Not only a set of drainage system is designed, but also a set of phosphorus removal device is added. The patent has the characteristics of less floor space and higher automation.

\section{Development process of SBR}

Some improvements in the development process of SBR focus on the process itself. After years of development, there are many kinds of deformation, which enrich the core of SBR process, such as ICEAS process, CASS process, cast process, DAT-IAT Process, etc [19]. However, the $3 \mathrm{~A}$ process and u-nitmjk process derived from SBR process have less application experience. [20].

\subsection{ICEAS process}

Wang Yingyi [21] used ICEAS process in urban sewage. ICEAS process added a partition board on the basis of traditional SBR tank, which divided the pretreatment area with small volume and the main reaction area with large volume. In the pretreatment area, BOD is adsorbed, which can reduce the impact of toxic substances and water on the main reaction zone, and improve the treatment efficiency of the whole system。Liu Jie [22] and others analyzed the feasibility of ICEAS in the treatment of urban sewage, and found out that the urban community with poor water quality uniformity is suitable to use ICEAS process for sewage treatment. Ding hang [23] and others analyzed and compared SBR process and ICEAS process, and concluded that ICEAS process has more advantages than SBR process under continuous water inflow condition.

\subsection{CASS Process}

Li Ruihui [24] adopted CASS process in the treatment of urban sewage. For some highly polluted effluent, anaerobic aerobic combined treatment process is usually used [25]. The reason is that the energy consumption of anaerobic process is lower than that of aerobic process, and the aerobic process can solve the defect that the 
effluent of anaerobic process is not up to standard. The two complementary methods can simultaneously remove organic matter, $\mathrm{N}$ and $\mathrm{P}$. Cass tank is in the cycle of aerobic, anaerobic and aerobic, so it can remove organic matter better, and the effect of nitrogen and phosphorus removal is remarkable. Xu Yaosen [26] used CASS process in a small sewage treatment plant in Yunnan Province. From the operation results, the method successfully removed pollutants in the sewage and made the sewage meet the national discharge standard. Tian Lijiang [27] compared and analyzed SBR and CASS in terms of principle, characteristics and economy, so as to provide a theoretical basis for future research.

\subsection{DAT-IAT Process}

DAT-IAT system is a new form of SBR process, and its reaction mechanism is the same as that of continuous activated sludge process. [28] a continuous aeration (DAT) tank and an intermittent aeration (IAT) tank were replaced by a SBR tank. Compared with SBR tank, it is equivalent to adding a biological selection tank in front of the original process. Because Dat tank adopts continuous aeration, the stability of the whole system is greatly improved, and the denitrification capacity and sludge bulking limitation ability are also better than those of SBR process. Gu Wei, yuan Yajing [29] in the treatment of pharmaceutical effluent, the DAT-IAT Process was used to treat pharmaceutical effluent in view of the characteristics that the main components of the effluent were protein, sugar, lignin and cellulose, and the CODcr was relatively high. The results show that compared with the traditional SBR technology, DATIAT has higher aeration volume ratio and less blower, which reduces the equipment investment. Liu Jianjun [30] used DAT-IAT Process Combined with hydrolysis acidification pretreatment method to treat coating wastewater containing refractory organics, and the results showed that the treated effluent met the national discharge standard. Wu Wenbin [31] et al. Used DATIAT Process and acidification pretreatment to treat coating effluent, and the effluent quality met the national discharge standard. Fan Chenyu [32] designed a sewage treatment equipment based on DAT-IAT Process, which solved the problems of unstable effluent and sludge floating. Zhang Daqun [33] and other studies and analyzes the characteristics of DAT IAT process and the operation mode of equipment. The advantages and disadvantages of SBR method and dat IAT method are compared, and the emphasis is put on showing that dat IAT process is more suitable for the current effluent treatment status.

\subsection{SBBR process}

From the process principle, SBBR process is based on the operation mode of SBR process, which is one of the innovation of SBR process. [34]

Andrzej jucherski [35] and others analyzed the reliability of small SBBR process in effluent purification, and concluded that it was reliable in removing basic pollutants, but could not remove biological compounds. Zhang Fengzhi [36] aimed at the problem of difficult removal of organic matter and ammonia nitrogen compounds in pharmaceutical effluent, SBR and SBBR processes were used to compare their treatment capacity in nitrogen removal, and the optimal carbon nitrogen ratio of denitrification effluent was obtained. Li Heng [37] studied the impact resistance and related application of SBBR process in the treatment of detergent effluent. The results show that the biofilm process can adapt to the effluent quality with lower biochemical properties and has good impact resistance. Zhang Xiaoling [38] and others studied the start-up of SBR process and SBBR process in single-stage autotrophic nitrogen removal. The results showed that the biological phase of SBBR was diversified and the biomass was high when the ammonia nitrogen removal rate of SBBR was almost the same.

\section{Conclusion and Prospect}

Generally speaking, SBR is a kind of sewage treatment technology which is still developing, and the relevant management platform and management mode need to be constantly updated and improved. The traditional SBR technology has the disadvantages of long treatment cycle, frequent switching of inlet and outlet water, high requirements for equipment automation and large water level change. The relevant improved technologies also have large sludge return flow and low volume utilization rate, so it is necessary to increase stirring to achieve the effect of phosphorus removal. In general, the improvement of technology is more efficient than the improved process, but the related R \& D investment is large, and the $\mathrm{R} \& \mathrm{D}$ cycle will be relatively long.

At present, with the increasing population, the sewage treatment problem has become a major problem hindering human development. Governments of various countries need to continuously increase the development and experience accumulation of SBR technology. Although the operation of SBR effluent treatment process and related improved process has been very mature in China, there is still a lot of room for improvement on how to adjust the operation mode synchronously according to the change of sewage treatment capacity and pollution degree. It includes the monitoring of sewage composition, the optimization of automation equipment and the improvement of the whole treatment system for the impact of pollutants. In order to realize the real significance of efficient treatment of sewage treatment, SBR process undoubtedly provides us with a reference answer. China should strengthen the technical capital investment of relevant universities and enterprises in this respect, promote the renewal and improvement of relevant processes, explore suitable SBR effluent treatment measures for China's actual situation, strengthen the resource utilization and industrialization, so as to bring more economic and social benefits. 


\section{References}

1. Zhong,Y.M.(2016) Study and Application of SBR for Effluent Treatment. J.Guangdong Chemical Industry,(11):57-59.

2. Luo,Z.Y.(2018) Application of SBR Process in Urban Sewage Treatment.J. Value Engineering,(16):180-182.

3. Li,H,Sun,R.Z,Chen.Z.X.(2002) Urban sewage treatment technology and engineering examples. Chemical Industry Press, Beijing.

4. Huang,S.Z,Niu,J.B.(2007) Sequencing batch activated sludge process and its application.J.Journal of TIANZHONG,22(2):84-87.

5. Chen,D.X.(2004) Development and Application of SBR Process.J.Copper Engineering,(01):67-69.

6. Zhu,K.K,Fei,X.N,Jiao,X.M.(2020) Effect of Illumination on the Expansion Performance of Activated Sludge in SBR Reactor.J. Journal of Tianjin CHENGJIAN University,(01):39-44.

7. Li,S.S,Zhu,S.F,Ma,B,R.(2020) Effects of $\mathrm{Cu} 2+$ on the Production and Composition of Extracellular Polymeric Substances in the Activated Sludge from a Sequencing Batch Reactor.J. Periodical of Ocean University of China,(02):107-115.

8. Song,L,Xu,W.B,Deng,G.Z.(2020) Advanced Treatment of Domestic Sewage with the Ecological Filter Bed and Response of Microbe to Temperature.J. Technology of Water Treatment, (07): 103-107.

9. Chang,S,Chang,Z,Sun,N.(2020) Sulfate Reduction to Promote Short-Cut Nitrification and Denitrification for the Treatment of FGD Tail Liquid in Power Plant.J. Technology of Water Treatment,(06):83-86.

10. Ning,G.Y,Niu,Y.J,Li,W.W.(2020) Dynamic effect of $\mathrm{C} / \mathrm{N}$ on microbial structure in SBR's biological nitrification process.J. China Environmental Science,(05):2053-2061.

11. Zhang,Z.J,Wang,S.H,Wang,J.L.(2008) Effect of alkalinity on the $[\mathrm{NH}+4-\mathrm{N}]$ ratio during partial nitrification in a sequencing batch reactor.J. Journal of Tsinghua University(Science and Technology), (09): 95-98.

12. Cai,L.Y,Xu,Z.W, Wang, J.L.(2008) Denitrifying bacteria of extended aeration sequencing batch system for treating leachate.J. Chemical Engineer, (02): 40-42.

13. He,Z.M,Qin,L,Li,Z.(2017) Improved-SBR Process for Treatment of Livestock Wastewater.J. Construction \& Design for Project,(06): 121-122.

14. Li,Y.H,Luo,Z.W.(2020) Effect of $\mathrm{FeCl} 3$ and PAC on SBR process operation.J. Construction and Budget,(07):60-63.

15. Duan,Y,Deng,S.H,Zhu,C.L.(2010) Research on Poultry Wastewater Treatment by Suspended Filler SBR.J. Safety and Environmental Engineering, 17(4): 10-12.
16. Yang,H.M,Wang,Y.K,Yang,C.R.(2017) Study on the Application of Effective Enzyme Accelerant Accell in the Treatment of Livestock and Poultry Wastewater by SBR.J. Industrial Safety and Environmental Protection,43(10):8-10.

17. Hyeongok Lee, Kilsoo Hyun.(2020) Effect of sequencing batch reactor (SBR)/granular activated carbon (GAC) bed and membrane hybrid system for simultaneous water reuse and membrane fouling mitigation. J.Environmental Engineering Research, 26(1):223-230.

18. Wang,Y.M,Shan,L.B,Wang,Y.J. A device for adding dephosphorization agent at the same time for SBR drainage.P.China, CN201922134871.3.202008-28.

19. LI,X.B,Zhang,J.F.(2008) Dac-iat process sewage treatment design.J. Science and Technology Innovation Herald,(08):88.

20. Shi,H.C.(2002) Comparison and selection of wastewater treatment technology.N. China Construction News,(012).

21. Wang,Y.Y. Improve the application of ICEAS technology in sewage treatment[D].Shanghai: East China University of Science and Technology,2014:4-6.

22. Liu,J,Zhong,Y.H,Qi,J.L.(2015) Study on the use of ICEAS technology in urban sewage.J. Hunan Papermaking, (03):27-28.

23. Ding,H,Li,Y.Y,Zhang,C.(1995) A new technique for wastewater treatment -SBR and improved ICEAS.J .Coal mine environmental protection, (04): 21-31.

24. Li,R.H.(2020) Application of CASS Technology in Urban Sewage Treatment Plant.J. Guangdong Chemical Industry,47(4): 134-136.

25. Du,Y,Zhou,B.H,Yuan,R.F.(2018) Treatment of large-scale livestock wastewater by UASB-SBR process.J. Chinese Journal of Environmental Engineering, (02):497-504.

26. Xu,Y.S.(2019) Application of CASS technology in a small sewage treatment plant in Yunnan Province.J. Resources Economization \& Environmental Protection, (05):78-79.

27. Tian,L.J,Yao,Z.B.(2003) Comparison of SBR process and CASS Process.J. Environmental Science and Technology,(02):14-15+21.

28. Zhang,D.Q,Wang,X.D. Dat-iat sewage treatment technology[M].Beijing: Chemical Industry Press, 2015.

29. Gu,W,Yuan,Y.J.(2011) An engineering example of TREATMENT of traditional Chinese medicine production wastewater by DAC-IAT process.J. Industrial Water \& Wastewater, (04):84-85+93.

30. Liu,J.J.(2014) Application of hydrolytic acidification +DAT-IAT process in treating coating wastewater.J. Equipment Technology,(04): 72-76.

31. Wu,W.B,Liu,S.J,Liu,Z.(2015) Treatment of automobile coating wastewater by a combination of 
physico-chemical - DAT-IAT - filtration process.J. Environmental Science \& Technology, (S1):205$208+214$

32. Fan,C.Y. The utility model relates to a sewage treatment equipment based on THE DAT-IAT process.P.China:CN201410716675.6.2016-06-29.

33. Zhang,D.Q,Wang.(2002) Research and application of DAT-IAT method in SBR .In:Water Industry Branch of China Society of Civil Engineering.Ningbo.6-7.

34. Mao,X.M,Zuo,Q.Y,Q,H.(2013) Overview of SBBR process and research progress at home and abroad.J. Journal of Chongqing University of Education,26(06):17-20+166.

35. Andrzej Jucherski, Andrzej Walczowski, Piotr Bugajski, et al. Technological reliability of domestic wastewater purification in a small Sequencing Batch Biofilm Reactor (SBBR). 2019, 224:340-347.

36. Zhang,F.Z.(2020) Study on deep denitrification of pharmaceutical wastewater by SBR and SBBR[D].Jinan: Shandong Jianzhu University,4-6.

37. Li,H. Application of SBBR process in cleaning agent wastewater treatment and study on impact resistance[D].Mianyang: Mianyang Normal University, 3 .

38. Zhang,X.L,Zhao,Y.H,Li, Z.Q(2016) A comparative study on the initiation of SBBR and SBR single stage autotrophic nitrogen removal process.In: Annual conference of Chinese Society of Environmental Sciences.Haikou.9. 